\title{
The feasibility of computer-assisted 3D navigation in multiple-level lateral lumbar interbody fusion in combination with posterior instrumentation for adult spinal deformity
}

\author{
Michael J. Strong, MD, PhD, MPH, Timothy J. Yee, MD, Siri Sahib S. Khalsa, MD, \\ Yamaan S. Saadeh, MD, Kevin N. Swong, MD, Osama N. Kashlan, MD, MPH, \\ Nicholas J. Szerlip, MD, Paul Park, MD, and Mark E. Oppenlander, MD \\ Department of Neurosurgery, University of Michigan, Ann Arbor, Michigan
}

OBJECTIVE The lateral lumbar interbody fusion (LLIF) technique is used to treat many common spinal degenerative pathologies including kyphoscoliosis. The use of spinal navigation for LLIF has not been broadly adopted, especially in adult spinal deformity. The purpose of this study was to evaluate the feasibility as well as the intraoperative and navigation-related complications of computer-assisted 3D navigation (CaN) during multiple-level LLIF for spinal deformity.

METHODS Retrospective analysis of clinical and operative characteristics was performed for all patients $>18$ years of age who underwent multiple-level CaN LLIF combined with posterior instrumentation for adult spinal deformity at the University of Michigan between 2014 and 2020. Intraoperative CaN-related complications, LLIF approach-related postoperative complications, and medical postoperative complications were assessed.

RESULTS Fifty-nine patients were identified. The mean age was 66.3 years (range $42-83$ years) and body mass index was $27.6 \mathrm{~kg} / \mathrm{m}^{2}$ (range $18-43 \mathrm{~kg} / \mathrm{m}^{2}$ ). The average coronal Cobb angle was $26.8^{\circ}$ (range $3.6^{\circ}-67.0^{\circ}$ ) and sagittal vertical axis was $6.3 \mathrm{~cm}$ (range -2.3 to $14.7 \mathrm{~cm}$ ). The average number of LLIF and posterior instrumentation levels were 2.97 cages (range 2-5 cages) and 5.78 levels (range 3-14 levels), respectively. A total of 6 intraoperative complications related to the LLIF stage occurred in 5 patients. Three of these were CaN-related and occurred in 2 patients (3.4\%), including 1 misplaced lateral interbody cage $(0.6 \%$ of 175 total lateral cages placed) requiring intraoperative revision. No patient required a return to the operating room for a misplaced interbody cage. A total of 12 intraoperative complications related to the posterior stage occurred in 11 patients, with 5 being CaN-related and occurring in 4 patients (6.8\%). Univariate and multivariate analyses revealed no statistically significant risk factors for intraoperative and CaN-related complications. Transient hip weakness and numbness were found to be in $20.3 \%$ and $22.0 \%$ of patients, respectively. At the 1-month follow-up, weakness was observed in $3.4 \%$ and numbness in $11.9 \%$ of patients.

CONCLUSIONS Use of CaN in multiple-level LLIF in the treatment of adult spinal deformity appears to be a safe and effective technique. The incidence of approach-related complications with CaN was $3.4 \%$ and cage placement accuracy was high.

https://thejns.org/doi/abs/10.3171/2020.5.FOCUS20353

KEYWORDS complications; computer-assisted navigation; lateral lumbar interbody fusion; scoliosis; spinal deformity; fluoroscopy

$\mathrm{T}$ HE lateral lumbar interbody fusion (LLIF) technique was first described by Ozgur et al. in 2006 and uses a retroperitoneal, transpsoas approach to the disc space. ${ }^{1}$ This approach is used to treat many spinal conditions, including degenerative disc disease, stenosis, spondylolisthesis, scoliosis, and spinal instability.
The LLIF technique offers several potential advantages over traditional posterior approaches, including reduced blood loss, lower postoperative pain, and shorter hospital stay. ${ }^{1-3}$ The LLIF technique has been reported for patients with adult spinal deformity, and is often combined with a posterior approach to achieve deformity correction and

ABBREVIATIONS ALIF = anterior lumbar interbody fusion; BMI = body mass index; CaN = computer-assisted 3D navigation; LL = lumbar lordosis; LLIF = lateral lumbar interbody fusion; OLIF = oblique lumbar interbody fusion; PI-LL = pelvic incidence-LL; PT = pelvic tilt; SVA = sagittal vertical axis; TLIF = transforaminal lumbar interbody fusion.

SUBMITTED April 27, 2020. ACCEPTED May 26, 2020.

INCLUDE WHEN CITING DOI: 10.3171/2020.5.FOCUS20353. 
arthrodesis. ${ }^{4-6}$ Given the limited direct visualization during the minimally invasive LLIF procedure and the close proximity to the lumbosacral plexus, neuromonitoring and fluoroscopy have been used, which can result in significant exposure to radiation for the patient and surgeon. ${ }^{7,8}$

The use of computer-assisted 3D navigation $(\mathrm{CaN})$ techniques for placement of pedicle screws and interbody cages has been reported to increase accuracy with reduced radiation exposure. ${ }^{8-16}$ Similarly, $\mathrm{CaN}$ has also been applied to the LLIF technique with appropriate accuracy and decreased need for fluoroscopy.13,17 The use of $\mathrm{CaN}$ for multiple-level LLIF in the treatment of patients with adult spinal deformity, however, is still relatively novel and has not been extensively studied.

In this study we retrospectively reviewed a cohort of patients undergoing multiple-level LLIF with $\mathrm{CaN}$ for spinal deformity. We evaluated intraoperative and perioperative complications as they related to the CaN LLIF approach. We hypothesized that navigated placement of interbody cages is safe and feasible in this patient population.

\section{Methods \\ Data Collection}

Patients who underwent a deformity correction surgery at the University of Michigan between 2014 and 2020 were identified. We defined spinal deformity as sagittal vertical axis (SVA) $>5 \mathrm{~cm}$, pelvic incidence-lumbar lordosis (PI-LL) mismatch $>10^{\circ}$, pelvic tilt $(\mathrm{PT})>20^{\circ}$, or coronal thoracolumbar curve $>30^{\circ}$. All patients were older than 18 years and had 2 or more navigated lateral interbody cages placed with subsequent posterior instrumentation. Data collected included age, gender, body mass index (BMI), race/ethnicity, osteopenia/osteoporosis status, smoking status, clinical symptoms, duration of symptoms, conservative management, radiographic parameters including SVA, coronal Cobb angle, PT, PI, LL, procedure characteristics including number of lateral interbody cages placed, number of posterior fusion levels, open versus percutaneous posterior screw placement, graft type, average blood loss, average surgical time, number of unplanned intraoperative CT image acquisitions, intraoperative complications, complications specifically related to navigation, postoperative complications, and length of stay. We excluded patients in whom $\mathrm{CaN}$ cage placement was not used, and who had nondegenerative causes of deformity such as deformity secondary to osteomyelitis or metastatic tumors to the spine. Patients were seen in the clinic by the primary surgeon at a minimum of 1 month after surgery.

Standing scoliosis radiographs were obtained for all patients pre- and postoperatively. Radiographic parameters were measured using the PACS (picture archiving and communication systems) built-in measuring tools. The Cobb angle was measured using the major thoracolumbar curve identifying the upper and lower end vertebrae. The SVA was measured using the plumb line from the midpoint of $\mathrm{C} 7$ and the distance from the posterior-superior corner of the sacrum. The pelvic incidence was measured using a line from the femoral head and a perpendicular line from the midpoint of the S1 superior endplate. The
PT was measured using a line from the femoral head and a line from the midpoint of the S1 superior endplate down to the bottom of the radiograph. Lumbar lordosis was measured by the angulation from the superior endplate of L1 to the superior endplate of S1.

Intraoperative CaN-related complications were separated into the LLIF stage and the posterior stage and defined as any $\mathrm{CaN}$ inaccuracy leading to misplaced interbody cage, breach of pedicle screw, or unplanned intraoperative CT acquisition. Neurological complications related to the LLIF approach were defined as transient (lasting < 1 month) or persistent (still present after 1 month) weakness or numbness in the lower extremity on the same side as surgery. Medical postoperative complications were also assessed.

Retrospective database analysis produced a list of 65 potentially eligible patients. Two patients did not undergo $\mathrm{CaN}$ interbody placement and were excluded from the study. An additional 4 patients did not have adequate follow-up and were also excluded. The study was approved by the University of Michigan Institutional Review Board.

\section{Surgical Technique}

This technique has previously been described in detail. ${ }^{1,17}$ Briefly, navigated placement of interbody cages from a lateral approach involved placing the patient in a lateral decubitus position on a flat radiolucent operating room table. A flank roll was placed to increase the interval between the lower end of the rib cage and iliac crest. An iliac pin with navigation reference frame was placed. The intraoperative CT fluoroscopy unit was brought into the field and 3D imaging of the spine was obtained for navigation purposes. Intraoperative navigation was used to plan the skin incision, assist with the approach and retractor placement, disc preparation, and placement of the interbody cage. Fluoroscopy was not typically used for skin marking or the approach for retractor placement, but was used sparingly to confirm cage positioning and to confirm navigation accuracy when needed. The most rostral-level LLIF was performed first, and proceeded sequentially caudally toward the navigation frame, thus maintaining navigation accuracy. Posterior instrumentation was performed either on the same day or in a staged fashion. Multimodal neuromonitoring was used during the operation, with triggered electromyography during the approach through the psoas muscle. In addition, in cases in which there were anatomical constraints (e.g., iliac crest), an oblique approach that involved traversing the anterior margin of the psoas muscle was used.

\section{Statistical Analysis}

A univariate analysis was performed to analyze demographics and clinical characteristics in relation to complications. Age, gender, BMI, osteopenia/osteoporosis, smoking status, number of LLIF levels, number of posterior fusion levels, average surgical time, and average blood loss (independent variables) were used to predict intraoperative complications (dependent variable) in a binomial logistic regression analysis. Statistical analysis was performed using the SPSS statistical package software (ver- 
sion 26; IBM Corp.) and statistical significance was defined as a value of $\mathrm{p}<0.05$.

\section{Results}

A total of 59 patients were included in this study (Table 1). The mean age at the time of surgery was 66.3 years (range $42-83$ years) and BMI was $27.6 \mathrm{~kg} / \mathrm{m}^{2}$ (range $\left.18-43 \mathrm{~kg} / \mathrm{m}^{2}\right)$. Thirty-four patients were female $(57.6 \%)$, 24 were male (40.7\%), and 1 was transgender male to female (1.7\%). All patients presented with symptomatic kyphoscoliosis. The average coronal Cobb angle was $26.8^{\circ}$ (range $3.6^{\circ}-67.0^{\circ}$ ), SVA was $6.3 \mathrm{~cm}$ (range -2.3 to 14.7 $\mathrm{cm})$, PI-LL mismatch was $17.5^{\circ}$ (range $-11.9^{\circ}$ to $\left.57.8^{\circ}\right)$, LL was $38.8^{\circ}$ degrees (range $3.7^{\circ}-84.1^{\circ}$ degrees), and PT was $23.7^{\circ}$ (range $7.5^{\circ}-47.6^{\circ}$ ).

Back pain was the most common presenting symptom in a total of 57 patients (96.6\%). Other neurological symptoms included 2 patients with neurogenic bowel or bladder (3.4\%), 11 with neurogenic claudication (18.6\%), 21 with lower-extremity weakness (35.6\%), 54 with lowerextremity radiculopathy (91.5\%), and 3 with myelopathy (5.1\%) in which 1 patient had a previous anterior cervical fusion. Most patients presented with symptoms lasting longer than 12 months (53 patients, 89.8\%). Conservative management had failed in all patients.

An average of 2.97 LLIF cages per patient were placed using CaN (range 2-5 cages), with a total of 175 cages placed (Table 2). Nineteen patients included supplementation with either transforaminal lumbar interbody fusion (TLIF; $\mathrm{n}=16$ ) or anterior lumbar interbody fusion (ALIF; $\mathrm{n}=3$ ). All 3 ALIFs were performed with the aid of an approach surgeon, with the patient lying lateral, and using an oblique trajectory. The average number of levels for posterior instrumentation was 5.78 (range 3-14 levels). The uppermost instrumented vertebrae ranged from T6 to L3 with the majority at T10 (13 patients), L1 (14 patients), L2 (15 patients), and L3 (11 patients). The lowermost instrumented vertebrae ranged from L3 to S2-alar-iliac with the majority at L5 (28 patients), S1 (6 patients), S1 with iliac screws (S1-iliac, 4 patients) and S2-alar-iliac (13 patients). Of the 23 patients in whom the posterior construct spanned L5-S1, 16 patients (70\%) underwent L5-S1 interbody fusion using either a TLIF or ALIF technique at that level.

A total of 36 patients underwent same-day posterior procedures (61.0\%), whereas 23 patients underwent staged posterior procedures $(39.0 \%)$. Posterior pedicle screw fixation was accomplished via an open (28 patients, $47.5 \%$ ) or percutaneous (30 patients, $50.8 \%$ ) technique. Within the percutaneous group, robot-assisted pedicle screw placement was used in 2 patients. One patient underwent a hybrid open and percutaneous posterior approach. When possible, autograft was used for fusion in addition to allograft $(n=22)$. A total of 19 patients $(32.2 \%)$ underwent posterior column osteotomies at the time of posterior instrumentation. No patient underwent pedicle subtraction osteotomy. In addition, 4 patients $(6.8 \%)$ underwent lumbar anterior ligament release via a lateral approach; none of these patients experienced approach-related complications. The average surgical time and estimated blood loss
TABLE 1. Demographics in the study population of 59 patients with LLIF

\begin{tabular}{|c|c|c|c|}
\hline Patient Variables & Value & Percentage & Range \\
\hline Age (yrs) & 66.3 & & $42-83$ \\
\hline $\mathrm{BMI}\left(\mathrm{kg} / \mathrm{m}^{2}\right)$ & 27.6 & & $18-43$ \\
\hline \multicolumn{4}{|l|}{ Gender } \\
\hline Female & 34 & $57.6 \%$ & \\
\hline Male & 24 & $40.7 \%$ & \\
\hline Other & 1 & $1.7 \%$ & \\
\hline \multicolumn{4}{|l|}{ Race/ethnicity } \\
\hline White/non-Hispanic & 56 & $94.9 \%$ & \\
\hline Black/non-Hispanic & 2 & $3.4 \%$ & \\
\hline Other/Hispanic & 1 & $1.7 \%$ & \\
\hline Osteopenia/osteoporosis & 28 & $47.5 \%$ & \\
\hline Smoker & 6 & $10.2 \%$ & \\
\hline \multicolumn{4}{|l|}{ Symptoms } \\
\hline Back pain & 57 & $96.6 \%$ & \\
\hline Neurogenic bowel or bladder & 2 & $3.4 \%$ & \\
\hline Neurogenic claudication & 11 & $18.6 \%$ & \\
\hline Motor deficits & 21 & $35.6 \%$ & \\
\hline Radiculopathy & 54 & $91.5 \%$ & \\
\hline Myelopathy & 3 & $5.1 \%$ & \\
\hline \multicolumn{4}{|l|}{ Location of pain } \\
\hline Back & 5 & $8.5 \%$ & \\
\hline Leg & 2 & $3.4 \%$ & \\
\hline Both & 52 & $88.1 \%$ & \\
\hline \multicolumn{4}{|l|}{ Duration of symptoms } \\
\hline$<3 \mathrm{mos}$ & 1 & $1.7 \%$ & \\
\hline $3-12$ mos & 5 & $8.5 \%$ & \\
\hline$>12$ mos & 53 & $89.8 \%$ & \\
\hline Average coronal Cobb angle $\left({ }^{\circ}\right)$ & 26.8 & & $3.6-67.0$ \\
\hline SVA (cm) & 6.3 & & -2.3 to 14.7 \\
\hline $\mathrm{PI}$-LL mismatch $\left({ }^{\circ}\right)$ & 17.5 & & -11.9 to 57.8 \\
\hline $\mathrm{LL}\left({ }^{\circ}\right)$ & 38.8 & & $3.7-84.1$ \\
\hline $\mathrm{PT}\left({ }^{\circ}\right)$ & 23.7 & & $7.5-47.6$ \\
\hline
\end{tabular}

Unless otherwise indicated, values are expressed as the number of patients and percentage.

for the CaN LLIF portion on days in which the procedures were staged was 278.6 minutes (range 126-635 minutes) and $99.1 \mathrm{~mL}$ (range $20-345 \mathrm{~mL}$ ), respectively (Table 2).

The average coronal Cobb angle correction was $18.1^{\circ}$ (range $2.1^{\circ}-60.2^{\circ}$ ) and lumbar lordosis correction was $7.6^{\circ}$ (range $-15.6^{\circ}$ to $36.6^{\circ}$ ). Figures 1 and 2 illustrate patients from this series with kyphoscoliosis, exemplified by preand postoperative radiographs.

The average length of hospital stay for this population was 7.4 days (range 3-28 days). Of note, the patient who stayed for 28 days underwent a 2-level lateral interbody fusion with a 14-level posterior construct and experienced multiple complications delaying her discharge (Table 2).

A total of 6 intraoperative complications related to the LLIF stage occurred in 5 patients $(8.5 \%)$ (Table 3). Of 
TABLE 2. Operative characteristics in the study population of 59 patients with LLIF

\begin{tabular}{|c|c|c|c|}
\hline Operative Variables & Value & Percentage & Range \\
\hline No. of LLIF levels & 175 total & & \\
\hline 2 & 19 & $32.2 \%$ & \\
\hline 3 & 25 & $42.4 \%$ & \\
\hline 4 & 13 & $22.0 \%$ & \\
\hline 5 & 2 & $3.4 \%$ & \\
\hline \multicolumn{4}{|l|}{ TLIF } \\
\hline L4-5 & 2 & $3.4 \%$ & \\
\hline L5-S1 & 14 & $23.7 \%$ & \\
\hline \multicolumn{4}{|l|}{ ALIF } \\
\hline L4-5 & 1 & $1.7 \%$ & \\
\hline L5-S1 & 2 & $3.4 \%$ & \\
\hline \multicolumn{4}{|c|}{ No. of posterior fusion levels } \\
\hline 3 & 13 & $22.0 \%$ & \\
\hline 4 & 14 & $23.7 \%$ & \\
\hline 5 & 9 & $15.3 \%$ & \\
\hline 6 & 4 & $6.8 \%$ & \\
\hline 7 & 3 & $5.1 \%$ & \\
\hline 8 & 1 & $1.7 \%$ & \\
\hline 9 & 7 & $11.9 \%$ & \\
\hline 10 & 6 & $10.2 \%$ & \\
\hline 11 & 1 & $1.7 \%$ & \\
\hline 14 & 1 & $1.7 \%$ & \\
\hline
\end{tabular}

Uppermost instrumented

vertebrae

\begin{tabular}{lr}
\hline T6 & 1 \\
\hline T7 & 1 \\
\hline T9 & 1 \\
\hline T10 & 13 \\
\hline T11 & 2 \\
\hline T12 & 1 \\
\hline L1 & 14 \\
\hline L2 & 15 \\
\hline L3 & 11 \\
\hline
\end{tabular}

Lowermost instrumented

vertebrae

\begin{tabular}{lrl}
\hline L3 & 1 & \\
\hline L4 & 7 & \\
\hline L5 & 28 & \\
\hline S1 & 6 & \\
\hline S1-iliac & 4 & \\
\hline S2-alar-iliac & 13 & \\
\hline Posterior approach & & \\
\hline Same day & 36 & $61.0 \%$ \\
\hline Staged & 23 & $39.0 \%$ \\
\hline Graft & & \\
\hline Allograft & 37 & $62.7 \%$ \\
\hline Autograft \& allograft & 22 & $37.3 \%$ \\
\hline$\quad$ & CONTINUED IN NEXT COLUMN $~$
\end{tabular}

» CONTINUED FROM PREVIOUS COLUMN

TABLE 2. Operative characteristics in the study population of 59 patients with LLIF

\begin{tabular}{|c|c|c|c|}
\hline Operative Variables & Value & Percentage & Range \\
\hline \multicolumn{4}{|l|}{ Posterior instrumentation } \\
\hline Open & 28 & $47.5 \%$ & \\
\hline Percutaneous & 28 & $47.5 \%$ & \\
\hline Percutaneous (robot) & 2 & $3.4 \%$ & \\
\hline Hybrid open-percutaneous & 1 & $1.7 \%$ & \\
\hline Length of stay (days) & 7.4 & & $3-28$ \\
\hline \multicolumn{4}{|l|}{ Average surgical time (mins) } \\
\hline Same day & 483.9 & & $129-1089$ \\
\hline Staged (navigated LLIF) & 278.6 & & $126-635$ \\
\hline $\begin{array}{l}\text { Staged (posterior } \\
\text { instrumentation) }\end{array}$ & 366.9 & & $97-724$ \\
\hline \multicolumn{4}{|l|}{$\begin{array}{l}\text { Average estimated blood loss } \\
(\mathrm{mL})\end{array}$} \\
\hline Same day & 668.7 & & $20-3400$ \\
\hline Staged (navigated LLIF) & 99.1 & & $20-345$ \\
\hline $\begin{array}{l}\text { Staged (posterior } \\
\text { instrumentation) }\end{array}$ & 883.0 & & $15-3200$ \\
\hline $\begin{array}{l}\text { Average coronal Cobb angle } \\
\text { correction }\left({ }^{\circ}\right)\end{array}$ & 18.1 & & $2.1-60.2$ \\
\hline Average LL correction $\left({ }^{\circ}\right)$ & 7.6 & & -15.6 to 36.6 \\
\hline
\end{tabular}

Unless otherwise indicated, values are expressed as the number of patients and percentage.

these, 3 were $\mathrm{CaN}$-related, including a case in which inaccurate $\mathrm{CaN}$ resulted in a misplaced interbody cage oriented posteriorly. This cage was subsequently removed, and an expandable cage was placed with the aid of fluoroscopy. An unplanned intraoperative $\mathrm{CT}$ acquisition was performed, and the remaining interbody cages were placed without complication. In another case, an unplanned intraoperative $\mathrm{CT}$ acquisition was performed due to $\mathrm{CaN}$ inaccuracy (Table 3). Therefore, a total of $3 \mathrm{CaN}$-related intraoperative complications occurred in 2 patients (3.4\%), with 1 misplaced lateral interbody cage $(0.6 \%$ of 175 total lateral cages placed) requiring intraoperative revision. No patient required a return to the operating room for misplaced interbody cage.

The 3 remaining intraoperative complications related to the LLIF stage included 1 diaphragmatic tear (1.7\%) repaired intraoperatively and 2 small pleural violations (3.4\%). One patient with a small pleural violation developed postoperative complications as detailed below. The other 2 patients did not develop any complication sequela.

A total of 12 intraoperative complications related to the posterior instrumentation stage occurred in 11 patients (18.6\%) (Table 3). A total of 5 were CaN-related including 1 incidence of pedicle screw breach. Further investigation demonstrated that the pedicle screws at this single level were inaccurately placed; 1 screw was medial and the contralateral screw was lateral. These screws were subsequently removed and replaced using a Jamshidi technique with K-wires and fluoroscopy without any neurological 


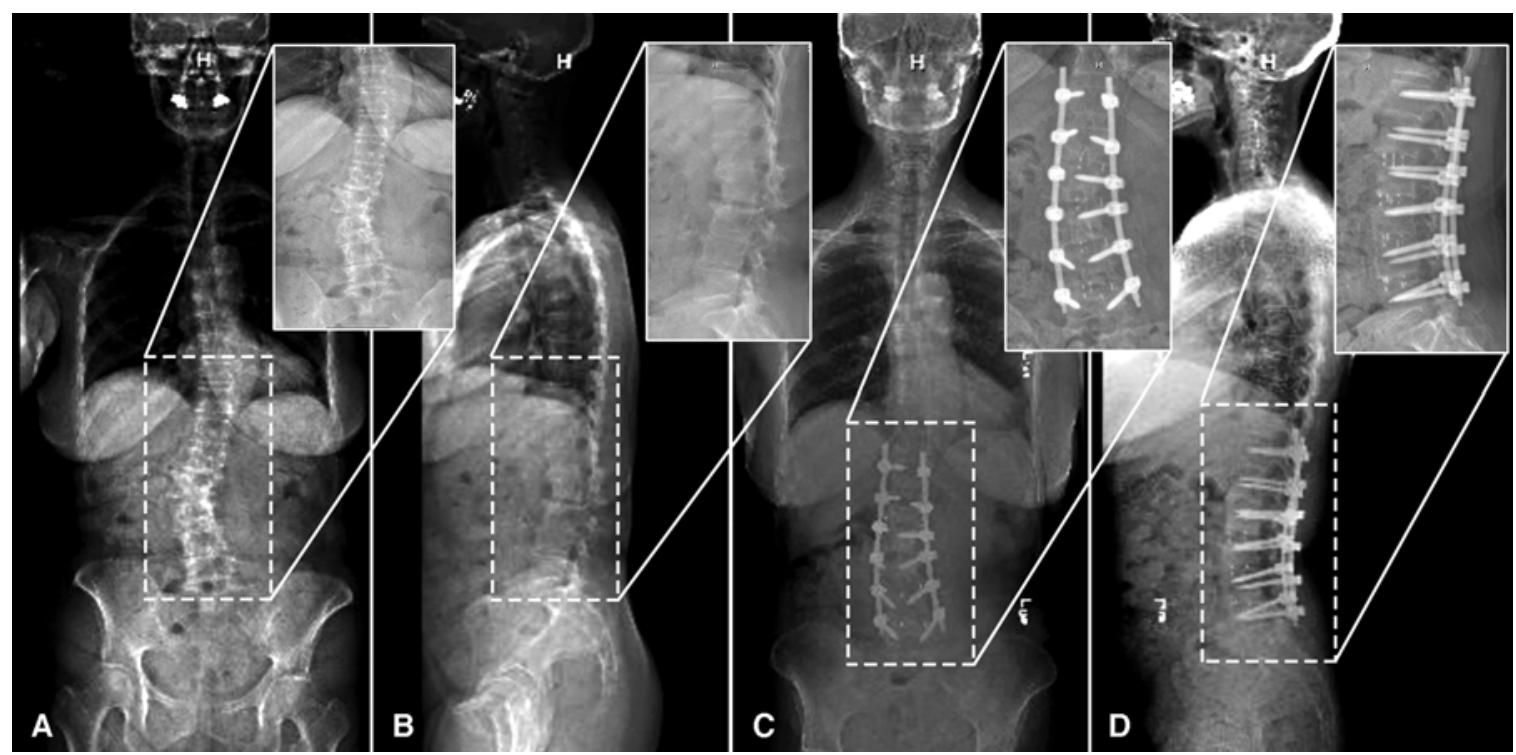

FIG. 1. A 70-year-old woman with a history of multiple lumbar laminectomies presented with progressive back pain and lumbar radiculopathy. Serial imaging revealed progressive lumbar scoliosis, adult spinal deformity with PI-LL mismatch, and postlaminectomy syndrome (A and B). The patient underwent L1-5 LLIF; the operative time was 322 minutes, with an estimated blood loss of $25 \mathrm{~mL}$. Two days later, open T12-L5 posterior instrumentation was performed; the operative time was 242 minutes, with an estimated blood loss of $350 \mathrm{~mL}(\mathbf{C}$ and $\mathbf{D})$.

compromise. The remaining pedicle screws were successfully placed with CaN after another unplanned intraoperative CT scan was performed. In 3 separate cases, unplanned intraoperative $\mathrm{CT}$ acquisitions were obtained due to $\mathrm{CaN}$ inaccuracies. Therefore, a total of $5 \mathrm{CaN}$-related intraoperative complications occurred in 4 patients $(6.8 \%)$ for the posterior instrumentation portion. The 7 remain- ing intraoperative complications were small durotomies (Table 3).

A binomial logistic regression analysis was performed to correlate different variables including age, gender, BMI, number of lateral interbody levels, number of posterior instrumentation levels, estimated blood loss, length of surgery, clinical symptoms, and open versus percutane-

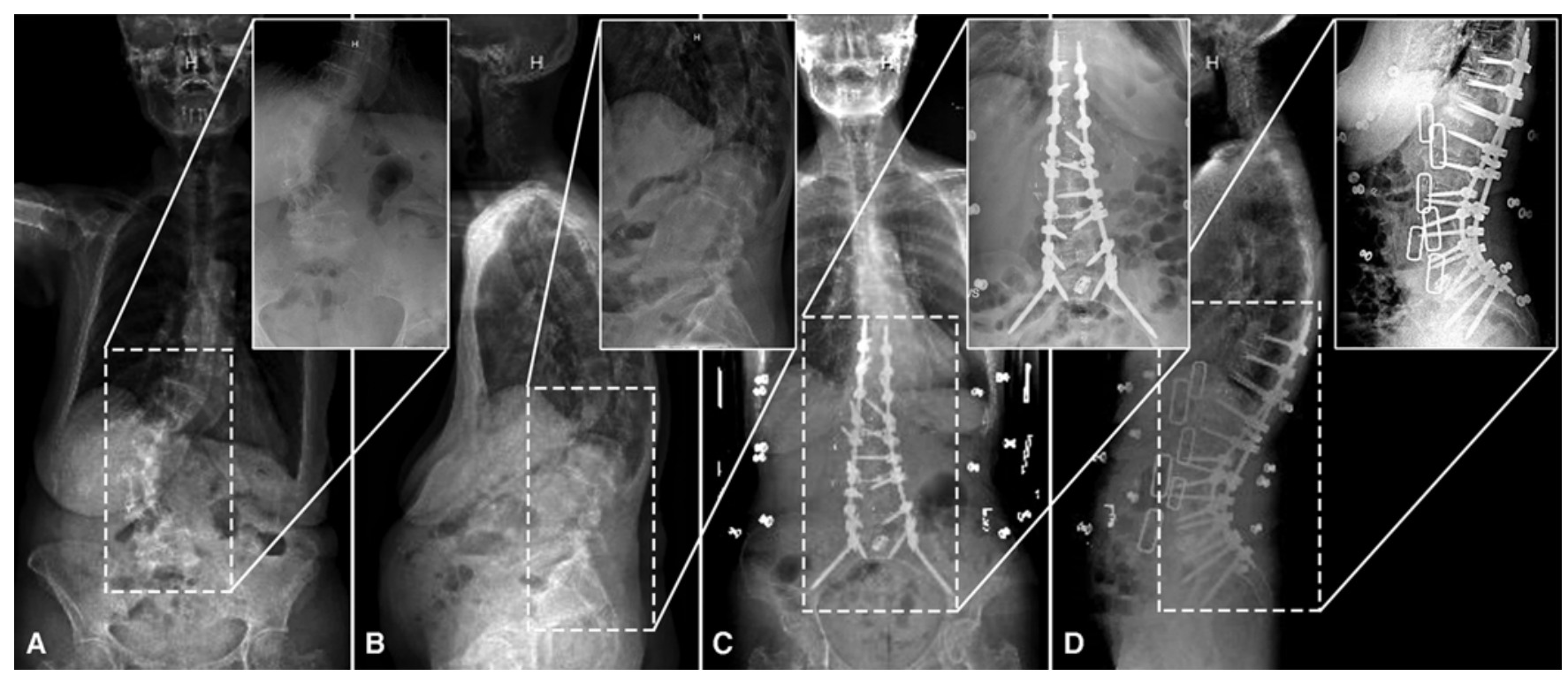

FIG. 2. A 71 -year-old woman with kyphoscoliosis ( $69^{\circ}$ thoracolumbar curve) presenting with back pain and lumbar radiculopathy (A and B) underwent T12-L5 LLIF; the operative time was 223 minutes, with an estimated blood loss of $50 \mathrm{~mL}$. The next day, open T10-pelvis posterior instrumentation was performed; the operative time was 366 minutes, with an estimated blood loss of 2000 $\mathrm{mL}$ (C and D). 
TABLE 3. Intraoperative and postoperative complications in 59 patients with LLIF

\begin{tabular}{|c|c|c|}
\hline Complication Variables & $\begin{array}{l}\text { No. of } \\
\text { Patients }\end{array}$ & Percentage \\
\hline \multicolumn{3}{|l|}{ Intraop complications (LLIF stage) } \\
\hline Pleural violation & 2 & $3.4 \%$ \\
\hline Diaphragm tear & 1 & $1.7 \%$ \\
\hline \multicolumn{3}{|l|}{ Navigation-related } \\
\hline $\begin{array}{l}\text { Misplaced interbody cage, revised using } \\
\text { fluoroscopy }\end{array}$ & 1 & $1.7 \% ; 0.6 \% *$ \\
\hline No. of unplanned intraop CT acquisitions & 2 & $3.4 \%$ \\
\hline \multicolumn{3}{|l|}{ Intraop complications (posterior stage) } \\
\hline Durotomy & 7 & $11.9 \%$ \\
\hline \multicolumn{3}{|l|}{ Navigation-related } \\
\hline $\begin{array}{l}\text { Breached pedicle screw, revised using } \\
\text { fluoroscopy }\end{array}$ & 1 & $1.7 \%$ \\
\hline $\begin{array}{l}\text { Number of unplanned intraop CT } \\
\text { acquisitions }\end{array}$ & 4 & $6.8 \%$ \\
\hline \multicolumn{3}{|l|}{ LLIF approach-related postop complications } \\
\hline $\begin{array}{l}\text { Pneumothorax, pulmonary edema, \& } \\
\text { hypoxia respiratory failure }\end{array}$ & 1 & $1.7 \%$ \\
\hline Transient weakness & 12 & $20.3 \%$ \\
\hline Persistent weakness & 2 & $3.4 \%$ \\
\hline Transient numbness & 13 & $22.0 \%$ \\
\hline Persistent numbness & 7 & $11.9 \%$ \\
\hline \multicolumn{3}{|l|}{ Postop complications $\dagger$} \\
\hline lleus & 9 & $15.3 \%$ \\
\hline Anemia requiring transfusion & 8 & $13.6 \%$ \\
\hline Urinary retention & 6 & $10.2 \%$ \\
\hline Superficial wound dehiscence & 2 & $3.4 \%$ \\
\hline Non-ST-elevation myocardial infarction & 2 & $3.4 \%$ \\
\hline Acute kidney injury & 2 & $3.4 \%$ \\
\hline $\begin{array}{l}\text { Atrial fibrillation } w / \text { rapid ventricular } \\
\text { response }\end{array}$ & 2 & $3.4 \%$ \\
\hline Deep venous thromboembolism & 1 & $1.7 \%$ \\
\hline Otherf & 4 & $6.8 \%$ \\
\hline
\end{tabular}

* Percentage of total lateral cages placed; $1 / 175$.

† Twenty-five total patients, with 9 patients having more than 1 complication. $\ddagger$ Includes meningitis, pneumonia, viral conjunctivitis, and urinary tract infection.

ous approach. None of the independent variables reached statistical significance related to intraoperative and $\mathrm{CaN}$ related complications for this surgical technique.

Postoperative complications related to the LLIF surgical approach included 1 patient with a small pleural violation who developed a pneumothorax (as described above), which resolved spontaneously. However, she subsequently developed pulmonary edema and respiratory failure, which extended her length of stay. Transient weakness in either hip flexion, knee extension, or dorsiflexion on the side of the LLIF surgery that was present postoperatively but resolved at the 1-month follow-up was noted in 12 patients (20.3\%). Two patients (3.4\%) continued to experience slight weakness with scores of 4+ in hip flexion at the time of the 1-month follow-up. Transient numbness in the lower extremity on the side of the LLIF surgery was reported in 13 patients (22.0\%). A total of 7 patients (11.9\%) continued to report some degree of numbness at the 1-month follow-up. However, this was not reported to be clinically significant.

Medical postoperative complications included 9 patients (15.3\%) with postoperative ileus, 8 patients $(13.6 \%)$ requiring transfusion, 6 patients $(10.2 \%)$ with urinary retention, 2 patients $(3.4 \%)$ with superficial posterior wound dehiscence treated with oral antibiotics, 2 patients (3.4\%) with non-ST-elevation myocardial infarction, 2 patients (3.4\%) with acute kidney injury, 2 patients $(3.4 \%)$ with atrial fibrillation with rapid ventricular response, 1 patient $(1.7 \%)$ with a deep venous thromoboembolism, and 4 patients with one of the following: meningitis, pneumonia, viral conjunctivitis, or urinary tract infection.

\section{Discussion}

The use of the LLIF technique to treat degenerative spinal conditions is gaining popularity, especially when coupled with $\mathrm{CaN}$. We have previously reported on the feasibility of using CaN LLIF for treating degenerative disc disease. ${ }^{11}$ In the present study, we analyzed the feasibility of using CaN for multiple-level LLIF in patients with adult spinal deformity. We demonstrate that use of the CaN LLIF technique in spinal deformity is feasible, with an acceptable rate of intraoperative and $\mathrm{CaN}$-related complications.

In this study we reported a total of 3 CaN-related complications associated with the LLIF portion occurring in 2 patients, and $5 \mathrm{CaN}$-related complications associated with the posterior instrumentation portion occurring in 4 patients. Our rate of CaN-related complications associated with the LLIF stage ( 2 of 59 patients, $3.4 \%$; including 1 of 175 lateral interbody cages, $0.6 \%$ ) is low and consistent with other techniques for interbody placement. Xi et al. demonstrated that use of $\mathrm{CaN}$ for the oblique lumbar interbody fusion (OLIF) technique resulted in an accuracy rate of $94.9 \%$, as assessed by postoperative lateral radiographs. ${ }^{18}$ Whereas $\mathrm{Xi}$ et al. evaluated only OLIF, in our study we had 1 misplaced interbody cage requiring intraoperative modification using the LLIF technique, which we attributed to $\mathrm{CaN}$ inaccuracy. This single incident suggests that use of $\mathrm{CaN}$ for placement of lateral lumbar interbody cages in the adult spinal deformity population is safe and accurate. We were unable to identify any existing studies in which CaN-related LLIF complications including need to abandon $\mathrm{CaN}$ for fluoroscopy or number of unplanned intraoperative CT acquisitions were directly evaluated. This is the first study to evaluate such complications in the adult spinal deformity population. The accuracy of using $\mathrm{CaN}$ has been well studied for pedicle screw placement ${ }^{11,19-21}$ and our pedicle screw accuracy-although not the focus of this study-was high, with only 1 incident of breached pedicle screws requiring intraoperative modification.

We reported 2 pleural violations and 1 diaphragm tear during the LLIF approach. The complications were rela- 
tively benign, with only 1 of the pleural violations resulting in postoperative complications - with a pneumothorax, pulmonary edema, and respiratory failure. These complications have been previously reported in the literature related to the LLIF approach..$^{22}$ Our rate of pleural complications $(5.1 \%)$ is at the low end of published data, which ranges from $2.5 \%{ }^{23}$ to $44 \% .{ }^{24}$ In our study no patient required chest tube placement.

Reported cases of transient hip flexion numbness and weakness is a relatively common postoperative complication of the LLIF technique because the surgical corridor traverses through the psoas muscle. ${ }^{25-28}$ The numbness and/or weakness is usually transient, as reported in a study conducted by Cummock et al. ${ }^{29}$ in which up to $90 \%$ of patients reported symptom resolution at their 1-year follow-up. In our study, we report 12 patients (20.3\%) with transient weakness and 13 patients $(22.0 \%)$ with transient numbness, which is consistent with other reported studies with ranges from roughly $20 \%$ to $40 \%$ for weakness and numbness. ${ }^{25,29,30}$ Two patients (3.4\%) experienced persistent weakness at the 1-month follow up. This is also consistent with reports in which the majority of patients experience complete resolution of their weakness. ${ }^{26}$ Interestingly, 7 patients $(11.9 \%)$ were still experiencing numbness at the 1-month follow-up, which was an improvement of roughly $41 \%$. The improvement in numbness observed in this study at 1-month follow-up is consistent with other reports in the literature. For example, Cummock et al. reported roughly $57 \%$ improvement in patients' numbness at 3 months. ${ }^{29}$

We report a total of 37 postoperative complications in 25 patients (42.4\%). Two patients experienced superficial wound dehiscence, which was treated with oral antibiotics. The remaining postoperative complications were medically related. Of note, the patient with the 28-day hospital stay experienced a durotomy intraoperatively. Furthermore, her hospital course was plagued with postoperative complications including postoperative ileus, urinary retention, anemia requiring transfusion, suspected meningitis, and a superficial wound dehiscence. She ultimately was discharged to a short-term acute-care hospital. This patient alone accounts for 6 of the total complications. Furthermore, 9 patients had more than 1 postoperative medially related complication.

The use of CaN in multiple-level LLIF for patients with adult spinal deformity has not been broadly adopted in comparison to fluoroscopy-based LLIF. A major advantage of $\mathrm{CaN}$ procedures is the reduction of fluoroscopy exposure of the surgeon. An additional advantage is the potential for improved surgical workflow, eliminating the need for the surgeon to wear lead and reducing the amount of intraoperative fluoroscope manipulation. Additionally, CaN-based LLIF may be superior to fluoroscopy in adult spinal deformity because the navigation can direct the approach to the coronally deformed spine and guide the cage placement between rotated vertebral bodies, maneuvers that can be a technical challenge. In order to maintain accuracy during a multiple-level LLIF procedure, we advocate performing the most rostral-level LLIF first and then proceeding sequentially caudally toward the navigation frame.

In our study, the average coronal Cobb angle correc- tion was $18.1^{\circ}$. This correction is similar to other reported studies in which LLIF was used for deformity correction with a range of $9.8^{\circ}-25.5^{\circ} .^{4-6,31-33}$ The lumbar lordosis correction in our study was $7.6^{\circ}$. This is also consistent with previous reports ranging from $3.8^{\circ}$ to $11^{\circ}$ of lordosis correction. ${ }^{4-6,31-33}$

This study is limited by retrospective data collection from a single institution. The analysis focused on intraoperative and perioperative complications of the multiplelevel CaN LLIF technique, and thus follow-up was limited. Potential late complications of the technique such as subsidence rate were not addressed. Additionally, long-term clinical outcomes were beyond the scope of this current study and further analysis is warranted. Last, our practice pattern is to obtain postoperative radiographs; CT scans were not routinely performed except in specific cases.

\section{Conclusions}

Use of CaN in multiple-level LLIF for adult spinal deformity is feasible. The rates of intraoperative and CaNrelated complications were low and did not result in significant harm. Approach-related complications with weakness and numbness were consistent with previous reports.

\section{Acknowledgments}

We thank Tom Cichonski for editorial assistance.

\section{References}

1. Ozgur BM, Aryan HE, Pimenta L, Taylor WR. Extreme Lateral Interbody Fusion (XLIF): a novel surgical technique for anterior lumbar interbody fusion. Spine J. 2006;6(4):435-443.

2. Salzmann SN, Shue J, Hughes AP. Lateral lumbar interbody fusion-outcomes and complications. Curr Rev Musculoskelet Med. 2017;10(4):539-546.

3. Rodgers WB, Gerber EJ, Patterson J. Intraoperative and early postoperative complications in extreme lateral interbody fusion: an analysis of 600 cases. Spine (Phila Pa 1976). 2011; 36(1):26-32.

4. Castro C, Oliveira L, Amaral R, et al. Is the lateral transpsoas approach feasible for the treatment of adult degenerative scoliosis? Clin Orthop Relat Res. 2014;472(6):1776-1783.

5. Phan K, Rao PJ, Scherman DB, et al. Lateral lumbar interbody fusion for sagittal balance correction and spinal deformity. J Clin Neurosci. 2015;22(11):1714-1721.

6. Sharma AK, Kepler CK, Girardi FP, et al. Lateral lumbar interbody fusion: clinical and radiographic outcomes at 1 year: a preliminary report. J Spinal Disord Tech. 2011;24(4): 242-250.

7. Uribe JS, Vale FL, Dakwar E. Electromyographic monitoring and its anatomical implications in minimally invasive spine surgery. Spine (Phila Pa 1976). 2010;35(26)(suppl):S368S374.

8. Mendelsohn D, Strelzow J, Dea N, et al. Patient and surgeon radiation exposure during spinal instrumentation using intraoperative computed tomography-based navigation. Spine $J$. 2016;16(3):343-354.

9. Nottmeier EW, Bowman C, Nelson KL. Surgeon radiation exposure in cone beam computed tomography-based, imageguided spinal surgery. Int J Med Robot. 2012;8(2):196-200.

10. Nottmeier EW, Pirris SM, Edwards S, et al. Operating room radiation exposure in cone beam computed tomographybased, image-guided spinal surgery: clinical article. J Neurosurg Spine. 2013;19(2):226-231. 
11. Joseph JR, Smith BW, Patel RD, Park P. Use of 3D CT-based navigation in minimally invasive lateral lumbar interbody fusion. J Neurosurg Spine. 2016;25(3):339-344.

12. Costa F, Tosi G, Attuati L, et al. Radiation exposure in spine surgery using an image-guided system based on intraoperative cone-beam computed tomography: analysis of 107 consecutive cases. J Neurosurg Spine. 2016;25(5):654-659.

13. Abdullah KG, Bishop FS, Lubelski D, et al. Radiation exposure to the spine surgeon in lumbar and thoracolumbar fusions with the use of an intraoperative computed tomographic 3-dimensional imaging system. Spine (Phila Pa 1976). 2012; 37(17):E1074-E1078.

14. Liu X, Joseph JR, Smith BW, et al. Analysis of intraoperative cone-beam computed tomography combined with image guidance for lateral lumbar interbody fusion. Oper Neurosurg (Hagerstown). 2018;14(6):620-626.

15. Chachan S, Bin Abd Razak HR, Loo WL, et al. Cervical pedicle screw instrumentation is more reliable with $\mathrm{O}$-arm-based 3D navigation: analysis of cervical pedicle screw placement accuracy with O-arm-based 3D navigation. Eur Spine J. 2018;27(11):2729-2736.

16. Kim TT, Johnson JP, Pashman R, Drazin D. Minimally invasive spinal surgery with intraoperative image-guided navigation. BioMed Res Int. 2016;2016:5716235.

17. Park P. Three-dimensional computed tomography-based spinal navigation in minimally invasive lateral lumbar interbody fusion: feasibility, technique, and initial results. Neurosurgery. 2015;11(suppl 2):259-267.

18. Xi Z, Chou D, Mummaneni PV, Burch S. The navigated oblique lumbar interbody fusion: accuracy rate, effect on surgical time, and complications. Neurospine. 2020;17(1): 260-267.

19. Gelalis ID, Paschos NK, Pakos EE, et al. Accuracy of pedicle screw placement: a systematic review of prospective in vivo studies comparing free hand, fluoroscopy guidance and navigation techniques. Eur Spine J. 2012;21(2):247-255.

20. Hecht N, Yassin H, Czabanka M, et al. Intraoperative computed tomography versus 3D C-arm imaging for navigated spinal instrumentation. Spine (Phila Pa 1976). 2018;43(5): 370-377.

21. Navarro-Ramirez R, Lang G, Lian X, et al. Total navigation in spine surgery; a concise guide to eliminate fluoroscopy using a portable intraoperative computed tomography 3-dimensional navigation system. World Neurosurg. 2017;100: $325-335$

22. Gabel BC, Schnell EC, Dettori JR, et al. Pulmonary complications following thoracic spinal surgery: a systematic review. Global Spine J. 2016;6(3):296-303.

23. Baaj AA, Dakwar E, Le TV, et al. Complications of the miniopen anterolateral approach to the thoracolumbar spine. $J$ Clin Neurosci. 2012;19(9):1265-1267.

24. Meredith DS, Kepler CK, Huang RC, Hegde VV. Extreme lateral interbody fusion (XLIF) in the thoracic and thoracolumbar spine: technical report and early outcomes. HSS J. 2013;9(1):25-31.

25. Tohmeh AG, Rodgers WB, Peterson MD. Dynamically evoked, discrete-threshold electromyography in the extreme lateral interbody fusion approach. J Neurosurg Spine. 2011; 14(1):31-37.
26. Lee YP, Regev GJ, Chan J, et al. Evaluation of hip flexion strength following lateral lumbar interbody fusion. Spine $J$. 2013;13(10):1259-1262.

27. Knight RQ, Schwaegler P, Hanscom D, Roh J. Direct lateral lumbar interbody fusion for degenerative conditions: early complication profile. J Spinal Disord Tech. 2009;22(1):34-37.

28. Gammal ID, Spivak JM, Bendo JA. Systematic review of thigh symptoms after lateral transpsoas interbody fusion for adult patients with degenerative lumbar spine disease. Int $J$ Spine Surg. 2015;9:62.

29. Cummock MD, Vanni S, Levi AD, et al. An analysis of postoperative thigh symptoms after minimally invasive transpsoas lumbar interbody fusion. J Neurosurg Spine. 2011; 15(1):11-18.

30. Moller DJ, Slimack NP, Acosta FL Jr, et al. Minimally invasive lateral lumbar interbody fusion and transpsoas approachrelated morbidity. Neurosurg Focus. 2011;31(4):E4.

31. Attenello J, Chang C, Lee Y-P, et al. Comparison of lateral lumbar interbody fusion (LLIF) with open versus percutaneous screw fixation for adult degenerative scoliosis. J Orthop. 2018;15(2):486-489.

32. Tormenti MJ, Maserati MB, Bonfield CM, et al. Complications and radiographic correction in adult scoliosis following combined transpsoas extreme lateral interbody fusion and posterior pedicle screw instrumentation. Neurosurg Focus. 2010;28(3):E7.

33. Anand N, Baron EM, Thaiyananthan G, et al. Minimally invasive multilevel percutaneous correction and fusion for adult lumbar degenerative scoliosis: a technique and feasibility study. J Spinal Disord Tech. 2008;21(7):459-467.

\section{Disclosures}

Paul Park reports consultation work with Globus Medical and $\mathrm{NuVasive}$ and royalties received from Globus Medical for an unrelated device. He also reports non-study-related grants for research from DePuy and ISSG. Mark Oppenlander is a consultant for Globus Medical, DePuy Spine, and LifeNet Health.

\section{Author Contributions}

Conception and design: Oppenlander, Strong, Kashlan, Szerlip, Park. Acquisition of data: Strong, Yee, Khalsa, Saadeh, Swong. Analysis and interpretation of data: all authors. Drafting the article: Oppenlander, Strong, Yee, Khalsa, Saadeh, Swong. Critically revising the article: Oppenlander, Strong. Reviewed submitted version of manuscript: all authors. Approved the final version of the manuscript on behalf of all authors: Oppenlander. Statistical analysis: Oppenlander, Strong, Yee, Khalsa, Saadeh, Swong. Study supervision: Oppenlander.

\section{Correspondence}

Mark E. Oppenlander: University of Michigan, Ann Arbor, MI. moppenla@med.umich.edu. 